\title{
MicroRNAs: exploring a new dimension in the pathogenesis of kidney cancer
}

Nicole MA White ${ }^{1,2}$, George M Yousef , $^{1 *}$

\begin{abstract}
Renal cell carcinoma (RCC) is the most common neoplasm of the adult kidney. The role of the von-Hippel-Lindeau $(\mathrm{VHL})$ tumour suppressor gene is well established in RCC with a loss of VHL protein leading to accumulated hypoxia-induced factor (HIF) and the subsequent transcriptional activation of multiple downstream targets. Recently, microRNAs (miRNAs) have been shown to be differentially expressed in RCC and their role in RCC pathogenesis is emerging. This month, in BMC Medicine, Gleadle and colleagues show that certain miRNAs are regulated by VHL in either a hypoxia-inducible factor (HIF)-dependent or HIF-independent manner in RCC. They also show that miRNA expression correlates with the survival of RCC patients.

In this commentary, we discuss the current understanding of the role of miRNAs in RCC and the different possible scenarios of their involvement in RCC pathogenesis. We also address their clinical significance as tumour markers, together with the potential use of miRNAs as therapeutic targets. Finally, we discuss some of the challenges that face the fast-evolving field of miRNAs, including the identification and validation of miRNA targets and the difficulties associated with establishing a link between miRNA expression and biological effects. A more thorough understanding of the biological nature of miRNAs and careful experimental planning will help us to reveal the complex role that miRNAs play in RCC pathogenesis.

See research article: http://www.biomedcentral.com/1741-7015/8/64
\end{abstract}

\section{Introduction}

This month, in BMC Medicine, Gleadle and colleagues show, for the first time, the effect of the von-HippelLindeau (VHL) tumour suppressor gene on microRNA (miRNA) expression in renal cell carcinoma (RCC) [1]. Their elegant work opens up a new dimension in the investigation of the role of miRNAs in the pathogenesis of RCC. It also highlights the potential challenges that need to be addressed in order to allow a better understanding of the complex relationship between miRNAs and cancer.

The VHL protein, which is defective in the majority of patients with RCC, plays a well characterized role in the pathogenesis of kidney cancer. Defective VHL leads to an accumulation of the hypoxia-inducible factor (HIF) and the activation of the hypoxic pathway of gene expression [2]. Anaerobic respiration seen in renal (and

\footnotetext{
* Correspondence: yousefg@smh.ca

'Department of Laboratory Medicine and the Keenan Research Centre in the Li Ka Shing Knowledge Institute, St Michael's Hospital, Toronto M5B 1W8,

Canada

Full list of author information is available at the end of the article
}

other) tumours can, therefore, be affected by the dysregulation of the VHL pathway. More recently, it has been shown that VHL has a number of other important functions that are HIF-independent [3]. The paper by Neal et al. identified a number of significantly dysregulated VHL-dependant miRNAs. Interestingly, whereas some of these miRNAs had altered expression as a consequence of HIF upregulation as previously documented in the literature, other miRNAs were dysregulated in a HIFindependent manner.

miRNAs are short non-coding, single-stranded RNAs that function by regulating protein translation and messenger RNA (mRNA) degradation of their target genes [4]. They have been shown to be involved in a number of critical biological processes, including cell development, differentiation and apoptosis [5,6]. It is estimated that about one-third of all human mRNAs are regulated by miRNAs [7]. Several independent studies have shown a strong link between dysregulated miRNAs and cancer, including breast, prostate, lung and kidney cancers [8-10]. Studies have shown that miRNAs affect the wellknown pathways involved in tumorigenesis, including 
the regulation of cell cycle, proliferation, metastasis, angiogenesis and others [11].

\section{Discussion}

As we proceed into more in-depth analyses of the role of miRNAs in cancer, it is now obvious that the relation of miRNAs with cancer is more complex than initially thought [11]. As shown in Figure 1, miRNA dysregulation can be either a cause or an effect of carcinogenesis. miRNAs can have oncogenic or tumour suppressor effects by inhibiting the protein production of their tumour suppressor or oncogenic targets, respectively. To add more complexity to this issue, some miRNAs have been shown to be downstream targets of oncogenic or tumour suppressor genes, such as p53 [12]. Moreover, it has been recently proposed that some miRNAs may be a part of the defence mechanism of the body's fight against carcinogenesis [13].
Evidence of the involvement of miRNAs in RCC pathogenesis is emerging. Recent studies have documented miRNA dysregulation in RCC compared to normal kidney tissue $[10,14]$. miRNAs can contribute to RCC pathogenesis at different levels. Some miRNAs have been shown to have an oncogenic effect on RCC [15]. The current study by Neal et al. showed that miRNA expression can be VHL-dependant.

It has been shown that several miRNAs are downstream effector molecules of the HIF-induced hypoxia response. miR-210 increases under hypoxic conditions and can target the iron-sulphur cluster protein (ISCU) which is involved in the mitochondrial electron transport chain, suggesting a potential mechanism for regulating anaerobic respiration in tumours $[1,16,17]$. Other miRNAs including miR-199a-5p and miR-135a [18] and $\mathrm{miR}-449 \mathrm{a} / \mathrm{b}$ [19] have also been shown to be regulated by hypoxia.

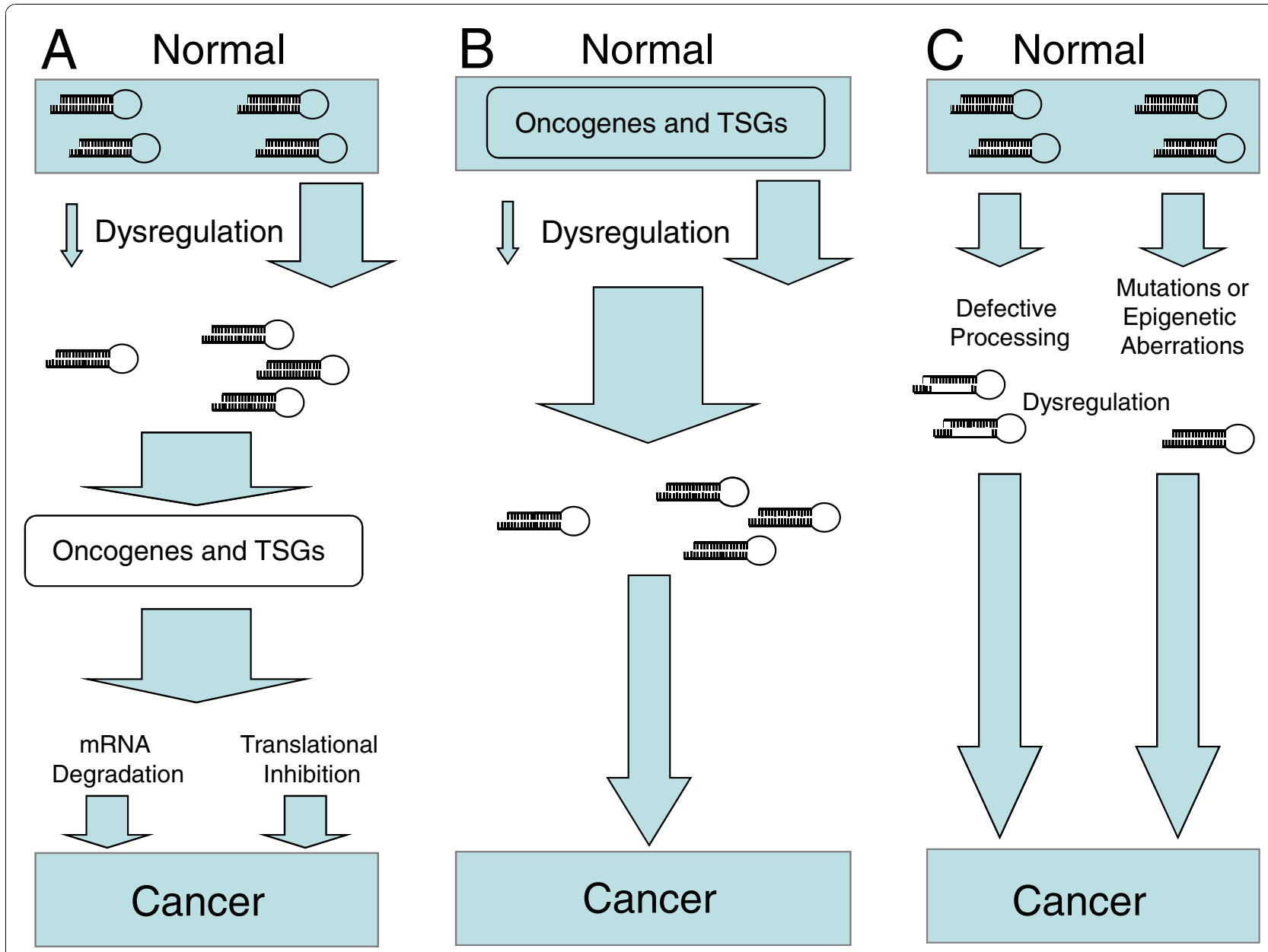

Figure 1 The complex involvement of microRNAs (miRNAs) in tumourigenesis. (A) Dysregulated miRNAs can have an oncogenic or tumour suppressor effect by inhibiting the protein production of their tumour suppressor or oncogenic targets, respectively. (B) Some miRNAs can be downstream targets of oncogenic of tumour suppressor genes, leading to their subsequent dysregulation and contribution to malignancy. (C) miRNA dysregulation can also be due to defective processing, mutations or epigenetic aberrations. TSG: tumour suppressor genes 
Recent experiments have shown that, apart from the hypoxia pathway, miRNAs can directly affect tumour proliferation through mechanisms that are yet to be identified. As shown in the current study, miRNAs, including let-7i, miR-31, miR-21 and members of the miR-17-92 cluster, may also be involved in non-HIF mediated pathways in RCC [1]. The miR-17-92 cluster has been shown to act as an oncogene in many different cancers. Members of this cluster have been shown to be involved in the regulation of MYC-induced cell proliferation by targeting E2F1 expression. miRNAs can directly control VHL, HIF, vascular endothelial growth factor receptor (VEGFR) and other key molecules in RCC pathogenesis $[8,10,11]$. Lastly, the regulation of miRNA expression in RCC is complex, involving several mechanisms such as mutations, epigenetic changes, chromosomal aberrations and defective processing. We have recently shown that chromosomal aberrations in RCC (gain or loss) are responsible, at least in part, for controlling miRNA expression [8, 10, Youssef Y, White NM, Grigull J, Krizova A, Samy C, Mejia-Guerrero S, Evans A, Jewett M, Yousef GM: MiRNA profiling in kidney cancer subtypes: accurate molecular classification and correlation with cytogenetic and mRNA data identifies unique and shared biological pathway, Submitted].

On the clinical frontier, miRNA expression levels can serve as diagnostic, prognostic and predictive tumour markers [14,20-22]. In the study by Neal et al. [1], the expression of miR-210 was shown to be a prognostic marker as its expression correlated with patient survival. Other studies have also shown a correlation between other miRNAs and the different subtypes of RCC [23] and tumour size [10]. Previous studies in multiple cancers have provided the rationale of using miRNAs as potential cancer therapeutic targets [24-26]. This is also applicable to RCC, as recent reports have suggested that key molecules in kidney cancer pathogenesis represent potential targets of miRNAs $[8,10]$. miRNA gene therapy is particularly interesting because it offers the appeal of targeting multiple genes simultaneously. This is especially exciting as RCC is notorious for being resistant to therapy, especially in the metastatic stage.

The accompanying paper raises interesting technical challenges. The first of these is the identification and validation of miRNA targets. Currently, there are numerous target prediction programs but all of them lack sensitivity and specificity. The experimental validation of miRNA targets is an essential step towards a better understanding of the role of miRNAs in cancer pathogenesis. This is not, however, a simple process considering that target prediction is based on (1) partial complementarity with target mRNAs, (2) a single miRNA can target a large number of genes and (3) the fact that the same mRNA can be targeted by multiple
miRNAs [21,27]. Establishing a high-throughput technique for the global validation of miRNA targets will need to be the corner-stone of miRNA research.

Although miRNA microarrays are a great initial tool for the discovery phase because they are operationdependent their results are not consistent, they need to be validated by a gold standard technique (for example, the use of quantitative real time PCR with gene-specific primers) as shown in the paper by Neal et al. Also, since an individual miRNA can have multiple targets, special care must be taken in the experimental design and the appropriate controls must be included. These include the co-transfection of the miRNA and its antagonist (the antagomir) and a control, or 'scramble', miRNA. The latter can be somewhat problematical as, given the fact that miRNA interaction with the target relies on imperfect complementarity, it may give unexpected results. In this case, site-directed mutagenesis of the miRNA sequence may be preferred.

Another interesting challenge for miRNA research is the establishment of a direct relationship between miRNA dysregulation, target dysregulation and the endpoint biological effect. This can be tricky as miRNAs can have an indirect effect on certain biological processes via alternate targets. Also, rather than being directly effected by the miRNA, the targeted gene may be a downstream target of these affected processes. Concurrent to developments in the miRNA field, improvements are required in animal models of diseases, in order to thoroughly test the effect of potential miRNA therapeutics.

\section{Conclusion}

Current evidence shows that miRNAs will have a significant impact on our understanding of the pathogenesis of RCC. More studies are required in order to accurately identify the mechanisms by which miRNAs affect RCC. Moreover, miRNAs present new potential tumour biomarkers that will improve our diagnostic, prognostic and predictive abilities and, consequently, cancer patient management. Since the discovery that miRNAs can have direct biological effects on cancer, there has been much interest in developing novel miRNA-based cancer therapies. The development of a useful miRNA therapy has the capability to revolutionize personalized cancer therapy. Although many challenges exist in the field of miRNA research, continuing technological advances will help to overcome these challenges and enable us to understand the effect of miRNAs on RCC - and other tumour - pathogenesis.

\section{Abbreviations}

HIF: hypoxia-induced factor; miRNA: microRNA; RCC: renal cell carcinoma; VHL: von-Hippel Lindeau. 


\section{Acknowledgements}

GMY is supported by grants from the Canadian Institute of Health Research (CIHR grant No. 86490), Canadian Cancer Society (CCS grant No. 20185), the Ministry of Research and Innovation, Government of Ontario and the Kidney Foundation of Canada.

\section{Author details}

'Department of Laboratory Medicine and the Keenan Research Centre in the Li Ka Shing Knowledge Institute, St Michael's Hospital, Toronto M5B 1W8, Canada. ${ }^{2}$ Department of Laboratory Medicine and Pathobiology, University of Toronto, Toronto M5S 1A8, Canada.

\section{Authors' contributions}

Both authors contributed equally to the development and writing of this manuscript.

\section{Competing interests}

The authors declare that they have no competing interests.

Received: 23 September 2010 Accepted: 21 October 2010 Published: 21 October 2010

\section{References}

1. Neal CS, Michael MZ, Rawlings LH, Van der Hoek MB, Gleadle JM: The VHLdependent regulation of microRNAs in renal cell cancer. BMC Med 2010, 8:64.

2. Turner KJ, Moore JW, Jones A, Taylor CF, Cuthbert-Heavens D, Han C, Leek RD, Gatter KC, Maxwell PH, Ratcliffe PJ, et al: Expression of hypoxiainducible factors in human renal cancer: relationship to angiogenesis and to the von Hippel-Lindau gene mutation. Cancer Res 2002, 62:2957-2961.

3. Young AP, Schlisio S, Minamishima YA, Zhang Q, Li L, Grisanzio C, Signoretti S, Kaelin WG Jr: VHL loss actuates a HIF-independent senescence programme mediated by $\mathrm{Rb}$ and p400. Nat Cell Biol 2008, 10:361-369.

4. Krol J, Loedige I, Filipowicz W: The widespread regulation of microRNA biogenesis, function and decay. Nat Rev Genet 2010, 11:597-610.

5. He L, Hannon GJ: MicroRNAs: small RNAs with a big role in gene regulation. Nat Rev Genet 2004, 5:522-531.

6. Ambros V: The functions of animal microRNAs. Nature 2004, 431:350-355

7. Lewis BP, Burge $C B$, Bartel DP: Conserved seed pairing, often flanked by adenosines, indicates that thousands of human genes are microRNA targets. Cell 2005, 120:15-20.

8. Chow TF, Youssef YM, lianidou E, Romaschin AD, Honey RJ, Stewart R, Pace KT, Yousef GM: Differential expression profiling of microRNAs and their potential involvement in renal cell carcinoma pathogenesis. Clin Biochem 2009, 43:150-158.

9. Schaefer A, Jung M, Kristiansen G, Lein M, Schrader M, Miller K, Stephan C Jung K: MicroRNAs and cancer: current state and future perspectives in urologic oncology. Urol Oncol 2010, 28:4-13.

10. White NM, Bao TT, Grigull J, Youssef YM, Girgis A, Diamandis M, Fatoohi E, Metias M, Honey RJ, Stewart R, et al: MiRNA profiling in clear cell renal cell carcinoma: biomarker discovery and the identification of potential controls and consequences of miRNA dysregulation. J Path 2010, in press

11. White NM, Fatoohi E, Metias M, Jung K, Stephan C, Yousef GM: Metastamirs: A stepping stone towards improved cancer management. Nature Rev Clin Oncol 2010, in press.

12. Chang TC, Wentzel EA, Kent OA, Ramachandran K, Mullendore M, Lee KH, Feldmann G, Yamakuchi M, Ferlito M, Lowenstein CJ, et al: Transactivation of miR-34a by $\mathrm{p} 53$ broadly influences gene expression and promotes apoptosis. Mol Cell 2007, 26:745-752.

13. Shalgi R, Pilpel $Y$, Oren M: Repression of transposable-elements - a microRNA anti-cancer defense mechanism? Trends Genet 2010, 26:253-259.

14. Jung M, Mollenkopf HJ, Grimm C, Wagner I, Albrecht M, Waller T, Pilarsky C, Johannsen M, Stephan $C$, Lehrach $H$, et al: MicroRNA profiling of clear cell renal cell cancer identifies a robust signature to define renal malignancy. J Cell Mol Med 2009, 19:3918-3928.

15. Chow TF, Mankaruos M, Scorilas A, Youssef $Y$, Girgis A, Mossad S, Metias S, Rofael $Y$, Honey RJ, Stewart R, et al: The miR-17-92 cluster is over expressed in, and has an oncogenic effect on, renal cell carcinoma. $J$ Urol 2010, 183:743-751.

16. Chen Z, Li Y, Zhang H, Huang P, Luthra R: Hypoxia-regulated microRNA210 modulates mitochondrial function and decreases ISCU and COX10 expression. Oncogene 2010, 29:4362-4368.

17. Favaro E, Ramachandran A, McCormick R, Gee H, Blancher C, Crosby M, Devlin C, Blick C, Buffa F, Li JL, et al: MicroRNA-210 regulates mitochondrial free radical response to hypoxia and krebs cycle in cancer cells by targeting iron sulfur cluster protein ISCU. PLOS ONE 2010, 5: e10345.

18. Gonsalves CS, Kalra VK: Hypoxia-mediated expression of 5-lipoxygenaseactivating protein involves HIF-1alpha and NF-kappaB and microRNAs 135a and 199a-5p. J Immunol 2010, 184:3878-3888.

19. Muth M, Theophile K, Hussein K, Jacobi C, Kreipe H, Bock O: Hypoxiainduced down-regulation of microRNA-449a/b impairs control over targeted SERPINE1 (PAI-1) m. J Transl Med 2010, 8:33.

20. Metias SM, lianidou E, Yousef GM: MicroRNAs in clinical oncology: at the crossroads between promises and problems. J Clin Pathol 2009, 62:771-776.

21. Fridman E, Dotan Z, Barshack I, David MB, Dov A, Tabak S, Zion O, Benjamin S, Benjamin $\mathrm{H}$, Kuker $\mathrm{H}$, et al: Accurate molecular classification of renal tumors using MicroRNA expression. J Mol Diagn 2010, 12:687-696.

22. Arsanious A, Bjarnason GA, Yousef GM: From bench to bedside: current and future applications of molecular profiling in renal cell carcinoma. Mol Cancer 2009, 8:20.

23. Petillo D, Kort EJ, Anema J, Furge KA, Yang XJ, Teh BT: MicroRNA profiling of human kidney cancer subtypes. Int J Oncol 2009, 35:109-114.

24. Seto AG: The road toward microRNA therapeutics. Int I Biochem Cell Biol 2010, 42:1298-1305.

25. Petrocca F, Lieberman J: Micromanipulating cancer: microRNA-based therapeutics? RNA Biol 2009, 6:335-340.

26. Wang V, Wu W: MicroRNA-based therapeutics for cancer. BioDrugs 2009, 23:15-23.

27. Yousef GM: microRNAs: a new frontier in kallikrein research. Biol Chem 2008, 389:689-694.

\section{Pre-publication history}

The pre-publication history for this paper can be accessed here: http://www.biomedcentral.com/1741-7015/8/65/prepub

doi:10.1186/1741-7015-8-65

Cite this article as: White and Yousef: MicroRNAs: exploring a new dimension in the pathogenesis of kidney cancer. BMC Medicine 2010 8:65

\section{Submit your next manuscript to BioMed Central and take full advantage of:}

- Convenient online submission

- Thorough peer review

- No space constraints or color figure charges

- Immediate publication on acceptance

- Inclusion in PubMed, CAS, Scopus and Google Scholar

- Research which is freely available for redistribution
C Biomed Central 